\title{
Additional Use of Alarm Systems in Wakefulness in the Treatment of Mono-Symptomatic Nocturnal Enuresis
}

\author{
Kosilov KV ${ }^{1}$, Loparev SA ${ }^{2}$, Kuzina IG ${ }^{3}$, Shakirova OV ${ }^{4}$, Zhuravskaya NS ${ }^{5}$, Lobodenko A $^{6}$
}

${ }^{1}$ Kosilov Kirill Vladimirovich MD, PhD, Professor, Department of Social Sciences, School of Humanities, '2Loparev Sergey Alexandrovich, $\mathrm{MD}$, Department of Urology, City polyclinic № 3. ${ }^{3}$ Kuzina Irina Gennadyevna, SD, PhD, Head of the Department of Social Science, ${ }^{4}$ Shakirova Olga Viktorovna, MD, PhD, Head of the Department of Theory and Methods of adaptive physical education, ${ }^{5}$ Zhuravskaya Natalia Sergeevna, MD, PhD, Professor of Department of theory and methods of adaptive physical education, ${ }^{6}$ Lobodenko Alexandra, undergrad of the Institute of Humanities. All from the Far Eastern Federal University, Vladivostok, Primorsky region, Russian Federation.

\section{Address for correspondence:}

K.V. Kosilov, MD, PhD

Ayax 10, F733, DVFU,

Vladivostok, Russian Federation,

RUVVO

Tel: +8-914-717-3915

E-mail address: oton2000@mail.ru

Acknowledgements: None

Funding: Nil

Conflict of Interest: None

Permission from IRB: Yes

Ethical dilemmas faced during study: None

\section{How to cite}

Kosilov VK, Alexandrovich LS, Gennadyevna KI, Viktorovna SO, Sergeevna ZN, Alexanda L. Additional Use of Alarm Systems in Wakefulness in the Treatment of MonoSymptomatic Nocturnal Enuresis. J Nepal Paediatr Soc 2016;36(1):8-13.

doi: http://dx.doi.org/10.3126/jnps.v36i1.14369

This work is licensed under a Creative Commons Attribution 3.0 License.

\begin{abstract}
Introduction: There are many factors associated with nocturnal enuresis in children and can be very challenging as regards its management. Consequently, misunderstanding could arise explaining the state when a child for years urinates in bed. The aim of this study was to investigate possibilities of increase of efficiency of alarm systems and decrease of time of result achievement in case of usage of such modernized therapy algorithm. Materials and methods: 452 children (307 boys and 145 girls) took part in the study. All patients were randomly divided into two groups prior to alarm systems therapy. Group A patients (206) were offered to use alarm system (Wet Stop/ BYE-WET by PALCO LABS, Inc (USA) in normal mode. Group B patients (246) were using alarm system in wakefulness - urinated on device catching sensor. Alarm intervention was carried out within 12 weeks, total period of observation over the patients- 5 months. Results: We found out that number of patients with urination in sleep after 3 months of therapy was reliably less in this group than in control (23.5 against 40.3 percent, $p<0.05$ ). Conclusion: Usage of alarm systems in patient's wakefulness in addition to standard treatment regimen was improved the efficiency of Alarm-therapy up to 76.5 percent. Day training with the usage of alarm systems reliably increased the number of dry nights and self-wakening in case of desire to urinate. Usage of alarm systems in wakefulness was safe and did not result in additional refusal from treatment.
\end{abstract}

Key words: Nocturnal enuresis, Alarm system, Monosynaptic enuresis

\section{Introduction}

Eficacy of primary monosymptomatic nocturnal enuresis - (PMNE) treatment still attracts many researchers. First of all, it is connected with its prevalence. According to the most upbeat assessments, PMNE prevalence is within the range of 1.6 percent 4.6 percent ${ }^{1,2}$, and it reaches 28.6 percent -20 percent -18.7 percent according to less ambitious estimates $3,4,5$. 
Such considerable spread of data about frequency of occurrence can be attributed not least to different understanding of PMNE diagnostics criteria. In the rules adopted by the International Children's Continence Society and National Clinical Guideline Centre (UK) ${ }^{6}$ PMNE is determined as the state when a child has at least 2 cases of nocturnal urination within a week. Consequently, misunderstanding can arise: how, for example, to explain the state when a child for years urinates in bed with mean frequency of 1.5-1.9 cases per week. Nevertheless, analysis of many publications allows determining approximate frequency of occurrence of PMNE at the level of 16.2 percent -15 percent -12.4 percent -7.5 percent $7,8,9,10$ with some variations depending on gender, place of residence, social status of parents and some other criteria. It means that PMNE takes one of the leading places among urologic pathology. PMNE frequency decreases with age $^{3}$, though not all researchers are of the same view ${ }^{11,12}$. Disorder of sleep architecture ${ }^{1,3,6,11}$, breathing troubles during sleep including obstructive sleep apnea ${ }^{11}$, family disposition, stress situations ${ }^{3,7}$ are among risk factors of enuresis development. Traditionally in consideration of problem of enuresis etiology a part of researchers pays attention to level of vasopressin (antidiuretic hormone) ${ }^{13}$, and many of them consider that it is important to eliminate presence of helminthes ${ }^{14}$. Certain researchers attach great importance to neurogenic urinary discomforts as possible risk factor of PMNE formation ${ }^{11,12}$.

Among numerous PMNE therapeutic schemes in recommendations of International Children's Continence Society and National Clinical Guideline Centre (UK) two well known and shown good results methods stand out. It is alarm systems therapy (alarm intervention) and influence by antidiuretic hormone ${ }^{6}$. Globally, both methods are working, although they have a range of disadvantages. In particular, alarm intervention requires long period of treatment that can bring to patients fatigue and loss of interest to treatment ${ }^{15,16,17,18,19,20}$. Earlier we proposed modernization of alarm-therapy consisting of usage of alarm systems in wakefulness in addition to usage in normal regimen ${ }^{21,22,23}$. The aim of this study was to investigate possibilities of increase of efficiency of alarm systems and decrease of time of result achievement in case of usage of such modernized therapy algorithm.

\section{Materials and Methods}

A total of 452 children (307 boys and 145 girls) between the age of 9-14 years (average age 12.3) took part in the study from January 1, 2012 till August 30,
2013. Selection of patients was carried out by means of random sampling. Condition of inclusion in the group was presence of at least two urinations during sleep within a week registered over the period of the last year. Presence of lower urinary tract dysfunction (including episodes of enuresis in wakefulness), any chronic somatic and mental diseases in the exacerbation phase were the conditions of exclusion from the group. According to recommendations of the International Children's Continence Society and National Clinical Guideline Centre (UK) $)^{6}$ questionnaire survey with the help of questionnaire OAB- $q^{24,25}$ and uroflowmetry ${ }^{26}$ were conducted to eliminate overactive detrusor before the study and upon its end. Prior to examination patients took standard laboratory analysis to exclude the signs of inflammatory process and helminthism. During the whole period of examination parents of children (or guardians) filled in urination diaries on a daily basis ${ }^{27}$ where they recorded number of urinations per day, their volume, number of enuresis per day, number of selfawakenings in case of desire to urinate as well as the episodes of enuresis in wakefulness (if available).

Examination and treatment scheme are represented at figure 1.

All patients were randomly divided into two groups prior to alarm systems therapy. Group A patients (206 persons) were offered to use alarm system (Wet Stop/ BYE-WET by PALCO LABS, Inc (USA) in normal mode. Group B patients (246 persons) were using alarm system in wakefulness - urinated on device catching sensor. Alarm intervention was carried out within 12 weeks, total period of observation over the patients- 5 months.

Assessment of therapy efficiency was carried out by variation of frequency of episodes of urination in sleep (enuresis episodes - EE), episodes of selfwakening from desire to urinate (episode of wakening - EW), number of dry nights. Study endpoint - state of these parameters at the end of treatment.

Obtained information was analyzed with the help of JMP SAS Statistical Discovery 8.0.2 (SAS Institute, Cary, NC, USA). Wilcoxon criterion was used for comparison of the results in groups; analysis of contingency of samplings was carried out by Spearman coefficient. Standard deviation $p<0.05$ was considered sufficient to confirm reliability of differences.

\section{Results}

The results of $O A B-q$ questionnaire survey: average score in-group $A-2.3$, in group $B-1.9$, patients with 
score $\geq 8$ were not detected. Uroflowmetry data: urine maximum volumetric flow rate $(\mathbf{Q}$ max) in group $A$ $19.4(6.9) \mathrm{ml} / \mathrm{s}$, in group $\mathrm{B}-22.5(7.0)$, average velocity of urination ( $Q$ mid) in group $A-16.4(4.6) \mathrm{ml} / \mathrm{s}$, in group B $-17.9(5.2) \mathrm{ml} / \mathrm{s}$. Time of maximum velocity reaching (TQ max) in group A - $5.9(1.2) \mathrm{s}$, in group $B$ -7.3 (1.4) $\mathrm{s}$. Time of waiting for the beginning of urination (Tw) in group A $5.9(2.2) \mathrm{s}$, in group B 4.3 (1.5) s.

Table 1 represents the results of comparison of average values of the parameters in question in groups within the whole period of observation. On all occasions resulting median values of number of urination episodes in sleep, self -awakening and dry nights differ from starting ones. However, in-group B reliable differences of all parameters are determined as early as after the second month of observation, but in-group $A$ it is relevant only for such parameter as number of selfwakening. Besides, in group B after three months of treatment values of parameters differ from starting ones with reliability $p<0.01$.

In comparison of median values of parameters in groups at the beginning of study it was determined that there are almost no differences between them, the values are practically identical. Upon completion of study, the situation turned out to be quite another: dynamics of median values was a bit different. Reliable differences were discovered between frequency of enuresis episodes (group A - 2.9 (0.9), group B - 1.3 (0.6), $p<0.05)$, number of dry nights $(A-3.9(0.7), B$
- $5.7(0.7), p<0.05$. The difference between frequency rates of self-awakening in groups was also considerable, but statistically unreliable. Comparison of dynamics of average values of parameters in groups allowed determining average correlation in all cases $(r=0.59$; $0.55 ; 0.67, p<0.05)$.

Figure 2 represents change in number of patients with number of enuresis episodes $\geq 2$ per week (in percent) over the whole course of treatment. Decrease of percentage of such children is recorded in both groups. However, right after the first month of treatment percentage of such patients in groups $A$ and $B$ reliably differs. After the second month, reliability of differences comprises $p \leq 0.01$, after the third month $-p \leq 0.05$. Percent of children with number of enuresis episodes $\geq 2$ per week in-group B was considerably lower in all chronological stages of treatment course. Correlation coefficient between analyzed parameter in groups comprised $r=0.69, p \leq 0.05$.

During the process of study, 19 (4.2 percent) persons stopped participation in it (7 in group $A, 12$ in group $B$ ). Among them 9 persons due to negative attitude to treatment procedure (3 in group A, 6 in group B), 5 persons - due to development of acute inflammatory disease (all from group B), 3 persons - due to school problems and unwillingness to follow recommendations (1 in group A, 2 in group B), 2 persons - due to another reasons not connected with treatment (group $A$ ).

Table 1: Dynamics of performance criteria of treatment within 3 months of follow $(n=452)$

\begin{tabular}{|c|c|c|c|c|c|c|c|c|c|c|c|c|}
\hline \multirow{2}{*}{$\begin{array}{c}\text { Performance } \\
\text { criteria } \\
\text { Period of } \\
\text { observation }\end{array}$} & \multicolumn{4}{|c|}{$\begin{array}{l}\text { The average number of } \\
\text { episodes of enuresis } \\
\text { (per week) }\end{array}$} & \multicolumn{4}{|c|}{$\begin{array}{l}\text { The average number of } \\
\text { "dry" nights (per week) }\end{array}$} & \multicolumn{4}{|c|}{$\begin{array}{c}\text { The average number of } \\
\text { self-awakenings (per week) }\end{array}$} \\
\hline & $\begin{array}{l}\text { prior to } \\
\text { treat }\end{array}$ & $\begin{array}{l}\text { after } 1 \\
\text { month }\end{array}$ & $\begin{array}{l}\text { after } 2 \\
\text { month }\end{array}$ & $\begin{array}{l}\text { after } 3 \\
\text { month }\end{array}$ & $\begin{array}{l}\text { prior to } \\
\text { treat }\end{array}$ & $\begin{array}{l}\text { after } 1 \\
\text { month }\end{array}$ & $\begin{array}{l}\text { after } 2 \\
\text { month }\end{array}$ & $\begin{array}{l}\text { after } 3 \\
\text { month }\end{array}$ & $\begin{array}{l}\text { prior to } \\
\text { treat }\end{array}$ & $\begin{array}{l}\text { after } 1 \\
\text { month }\end{array}$ & $\begin{array}{l}\text { after } 2 \\
\text { month }\end{array}$ & $\begin{array}{l}\text { after } 3 \\
\text { month }\end{array}$ \\
\hline Group A & 5.9 & 5.0 & 3.3 & $2.9^{*}$ & 2.0 & 3.3 & 3.9 & $3.9^{*}$ & 0.6 & 1.5 & $3.5^{*}$ & $3.8^{* *}$ \\
\hline$(n=206)$ & $(1.2)$ & $(1.3)$ & $(2.1)$ & $(0.9)$ & $(0.9)$ & $(1.3)$ & $(0.8)$ & $(0.7)$ & $(0.5)$ & $(1.1)$ & $(0.9)$ & $(0.7)$ \\
\hline Group B & 6.5 & 5.1 & $1.9^{*}$ & $1.3^{* *}$ & 1.7 & 2.7 & $5.0^{* *}$ & $5.7^{* *}$ & 0.6 & 1.3 & $2.6^{*}$ & $5.6^{* *}$ \\
\hline$(n=246)$ & $(1.5)$ & $(1.4)$ & $(0.8)$ & $(0.6)$ & $(0.7)$ & $(0.6)$ & $(1.1)$ & $(0.7)$ & $(0.3)$ & $(1.3)$ & $(1.1)$ & $(1.2)$ \\
\hline
\end{tabular}

Note: In parentheses is the standard deviation (SD). The significance of differences ${ }^{*} p<0.05 ;{ }^{* *}-p<0.01$. The table shows the significance of differences between the results of post-treatment (after 3 month) and intermediate results (prior to treat; after 1 month; after 2 month). 


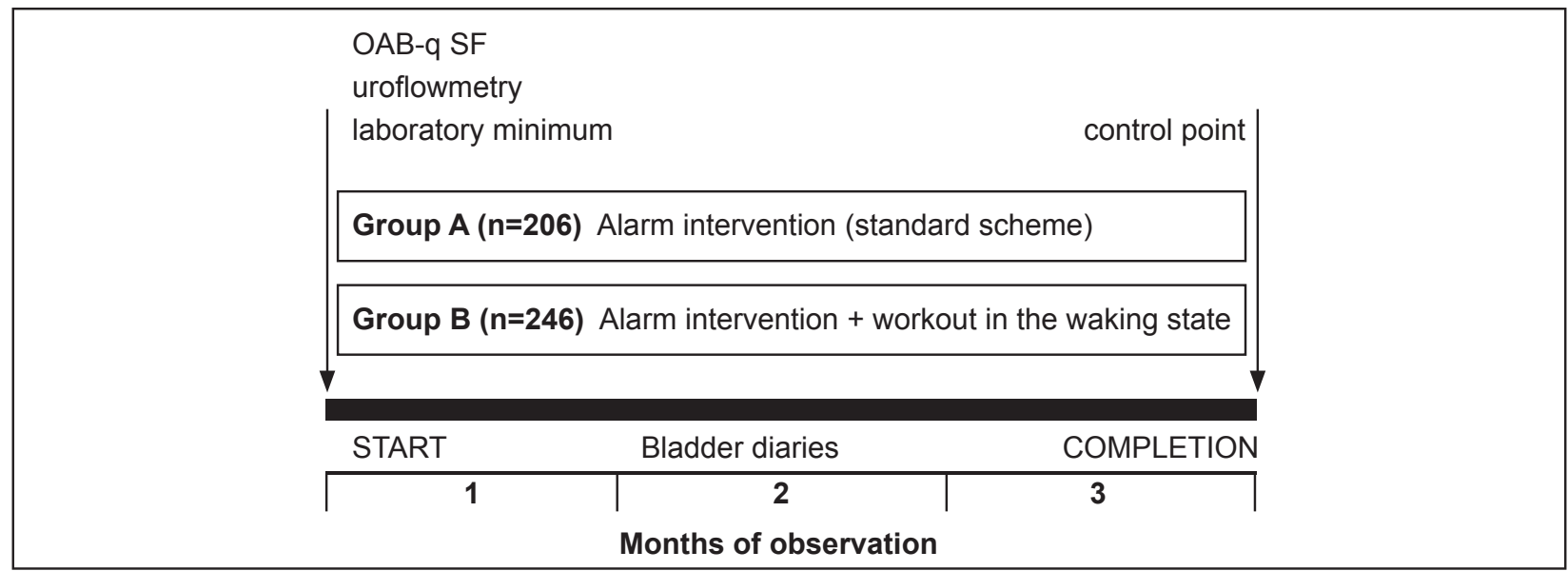

Fig. 1: The scheme of examination and treatment of patients suffering from PMNE $(n=452)$

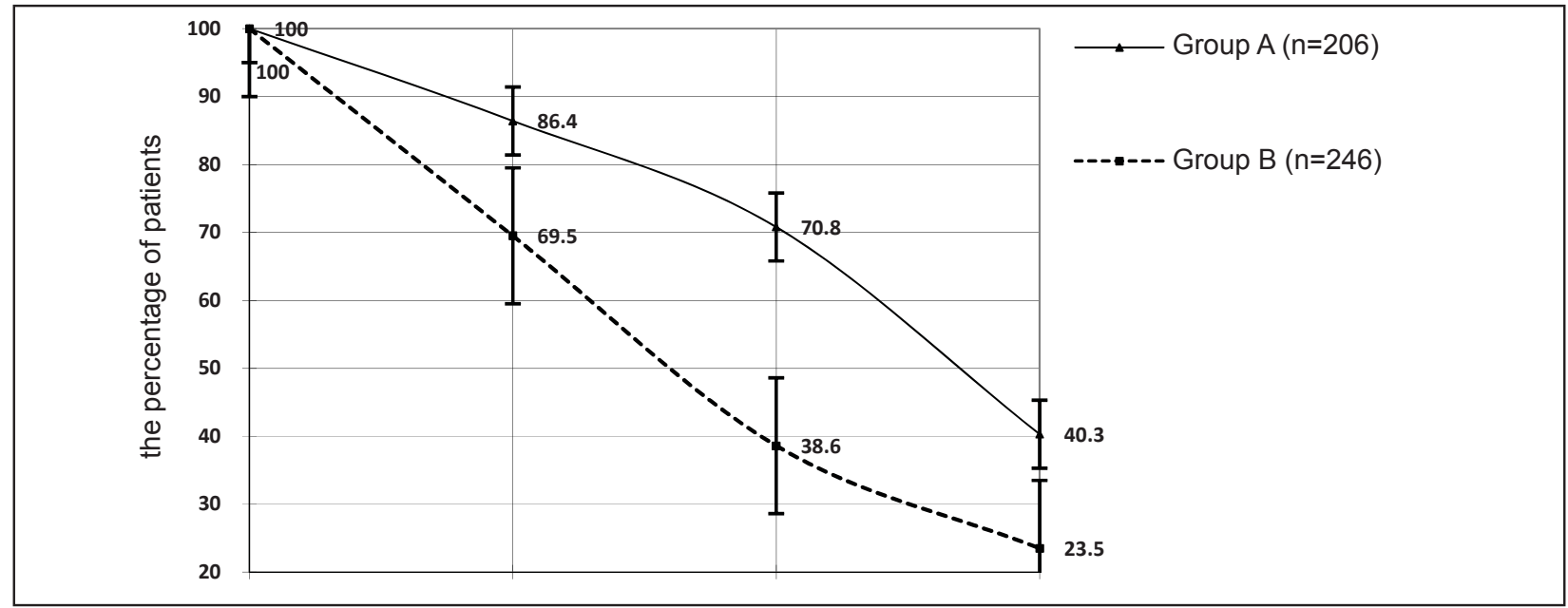

Fig 2: The dynamics of the proportion of patients with the number of episodes of urinary incontinence for more than two.

\section{Discussion}

Alarm intervention has been applied in treatment of nocturnal enuresis for several decades. Nowadays it is recommended by the International Children's Continence Society together with synthetic analog of antidiuretic hormone as the method of first-line therapy. Nevertheless, in spite of long history of application ${ }^{28}$ this method often does not bring to desired effect. Attempts to improve the schemes of alarm systems use are also being made nowadays $\mathbf{s}^{29,30,31,32,33}$.

In our study we compared the results of application of alarm system in two groups of 9-14-year-old patients in traditional variant and using permanent training in the daytime, in wakefulness. After analysis of the results we found out that number of patients with urination in sleep after three months of therapy is reliably less in this group than in control one (23.5 against 40.3 percent, $p<0.05$ ).

What is the reason for such increase of efficiency in case of use of devices in wakefulness? To our opinion, one of possible explanations lies in physiology of trained reflexes. On the one hand, majority of researchers do not deny connection of enuresis with sleep disorder. On the other hand, they admit that PMNE is not connected with detrusor dysfunction ${ }^{34,35,36}$. Standard scheme of Alarm intervention allows moderately increasing flow of afferent impulses in case of desire to urinate in sleep, making it sufficient to change activity of reticular formation, and awaking the patient. But such stimulus is not often enough, in fine positive result is usually registered by a little bit more than half of patients. In this situation additional training with the use of alarm system in wakefulness strengthens weak or lost reflex for awakening in case of desire to urinate in sleep, makes it more stable ${ }^{19,29,30}$.

Certainly, mentioned arguments are not exhaustible, and they represent only one of possible versions of explanation of obtained result. Probably, follow-up studies will let arriving to better understanding of the processes taking place during additional trainings with alarm systems. 


\section{Conclusion}

Usage of alarm systems in patient's wakefulness in addition to standard treatment regimen was improved the efficiency of Alarm-therapy up to 76.5 percent. Day

\section{References}

1. Esposito $M$, Gallai $B$, Parisi $L$ et al. Primary nocturnal enuresis as a risk factor for sleep disorders: an observational questionnaire-based multicenter study. Neuropsychiatr Dis Treat 2013;9:437-43.

2. Su MS, Li AM, So HK et al. Nocturnal enuresis in children: prevalence, correlates, and relationship with obstructive sleep apnea. J Pediatr 2011;159(2):23842.e1.

3. Aljefri HM, Basurreh OA, Yunus F. et al. Nocturnal enuresis among primary school children. Saudi J Kidney Dis Transp/ 2013;24(6):1233-41.

4. Merhi BA, Hammoud A, Ziade F. et al. Monosymptomatic nocturnal enuresis in lebanese children: prevalence, relation with obesity, and psychological effect. Clin Med Insights Pediatr 2014;8:5-9.

5. Hashem M, Morteza A, Mohammad K, Prevalence of nocturnal enuresis in school aged children: the role of personal and parents related socio-economic and educational factors. Iran J Pediatr 2013;23(1):59-64.

6. Nocturnal Enuresis: The Management of Bedwetting in Children and Young People. National Clinical Guideline Centre (UK). London: Royal College of Physicians (UK); 2010.

7. Dolgun G, Savaser S, Balci S. Prevalence of nocturnal enuresis and related factors in children aged $5-13$ in istanbul. Iran J Pediatr 2012 Jun;22(2):205-12.

8. Yazici CM, Abali R, Tasdemir N. et al. Is nocturia of young adulthood a remnant of childhood nocturnal enuresis? Int Urogynecol J. 2014 Feb;25(2):273-8; quiz 277-8

9. Karničnik $\mathrm{K}$, Koren $\mathrm{A}$, Kos $\mathrm{N}$ et al. Prevalence and quality of life of slovenian children with primary nocturnal enuresis. Int J Nephrol 2012;2012:509012.

10. Yazici CM, Nalbantoglu B, Topcu B. et al. Prevalence of nocturnal enuresis and associated factors in schoolchildren in Western Turkey. Can J Urol 2012;19(4):6383-8.

11. Baek $M$, Park $K$, Lee $H$ et al. A nationwide epidemiological study of nocturnal enuresis in Korean adolescents and adults: population based cross sectional study. J Korean Med Sci 2013;28(7):1065-70.

12. Bascom A, Penney $T$, Metcalfe $M$ et al. High risk of sleep disordered breathing in the enuresis population. J Urol 2011;186(4 Suppl):1710-3. training with the usage of alarm systems reliably was increased the number of dry nights and self-wakening in case of desire to urinate. Usage of alarm systems in wakefulness was safe and did not result in additional refusal from treatment.

13. Chang JW, Yang LY, Chin TW, et al. Clinical characteristics, nocturnal antidiuretic hormone levels, and responsiveness to DDAVP of school children with primary nocturnal enuresis. World J Urol 2012;30(4):567-71.

14. Otu-Bassey IB, Useh MF, Alaribe AA. The posttreatment effects of enterobiasis on the occurrence of enuresis among children in Calabar, Nigeria.Asian Pac J Trop Med 2011;4(4):315-9.

15. Bottomley $\mathrm{G}$. Treating nocturnal enuresis in children in primary care. Practitioner 2011;255(1741):23-6, 2-3.

16. Vande Walle J, Rittig S, Bauer $S$ et al. Practical consensus guidelines for the management of enuresis Eur J Pediatr 2012;171(6):971-83.

17. Kaneko K. Treatment for nocturnal enuresis: the current state in Japan. Pediatr Int 2012;54(1):8-13.

18. Deshpande AV, Caldwell PH. Medical management of nocturnal enuresis. Paediatr Drugs 2012;14(2):71-7.

19. Ozgür BC, Ozgür $S$, Doğan V, Orün UA.The efficacy of an enuresis alarm in monosymptomatic nocturnal enuresis. Sing Med J 2009; 50(9):879-80.

20. Butler RJ, Gasson SL.Enuresis alarm treatment. Scand J Urol Nephrol 2005;39(5):349-57.

21. Kosilov KV, Itskovich Al. Method for the treatment of enuresis in children. Application Number: 2002111959/14 Patent RU (11) 2216361 (13) C1(51) 7 A61N1/18. Published: 2003.11.20.

22. Kosilov K.V., Antonenko F.F., Itskovich Al. Enuresis in children: risk factors, pathogenesis and treatment. The Far Eastern Science; 2003.

23. Kosilov KV, Kulieva M, et al. A differentiated approach to the treatment of enuresis in children, depending on the level and nature of the defeat of autonomic regulation. J Pediatr [Russ] 2006;(5): 21-27.

24. Arlandis S, Ruiz MA, Errando C. et al. Quality of life in patients with overactive bladder: validation and psychometric properties of the Spanish Overactive Bladder Questionnaire-short Form. Clin Drug Invest 2012;32(8):523-32.

25. McKown $\mathrm{S}$, Abraham L, Coyne $\mathrm{K}$ et al. Linguistic validation of the N-QOL (ICIQ), OAB-q (ICIQ), PPBC OAB-S and ICIQ-MLUTSsex questionnaires in 16 languages. Int J Clin Pract 2010;64(12):1643-52

26. Gupta DK, Sankhwar SN, Goel A. Uroflowmetry nomograms for healthy children 5 to 15 years old. $J$ Urol 2013;190(3):1008-13. 
27. Kwak KW, Park KH. Clinical inconsistency of lower urinary tract symptoms between questionnaire and bladder diary in children with nocturnal enuresis. J Urol 2008 ;180(3):1085-9 \& 1089-90.

28. E Fleming Electronic bed wetting alarm and toilet trainer. Br Med J (Clin Res Ed). 1982 August 14; 285(6340): 512.

29. Robertson B, Yap K, Schuster S. Effectiveness of an alarm intervention with overlearning for primary nocturnal enuresis. J Pediatr Urol 2014;10(2):241-5.

30. Axelrod MI, Tornehl C, Fontanini-Axelrod A. Enhanced response using a multicomponent urine alarm treatment for nocturnal enuresis. J Spec Pediatr Nurs 2014;19(2):172-82.

31. Ahmed AF, Amin MM, Ali MM, Efficacy of an enuresis alarm, desmopressin, and combination therapy in the treatment of Saudi children with primary monosymptomatic nocturnal enuresis. Korean $\mathrm{J}$ Urol 2013;54(11):783-90.
32. Perrin N, Sayer L, While A. The efficacy of alarm therapy versus desmopressin therapy in the treatment of primary mono-symptomatic nocturnal enuresis: a systematic review. Prim Health Care Res Dev 2013:111.

33. Schulz-Juergensen S, Langguth A, Eggert P. Effect of alarm therapy on conditioning of central reflex control in nocturnal enuresis: pilot study on changes in prepulse inhibition (PPI). Pediatr Nephrol 2014;29(7):1209-13.

34. Kiddoo DA. Nocturnal enuresis. Can Med Assoc J 2012;184(8):908-11.

35. Norfolk S, Wootton J. Nocturnal enuresis in children. Nurs Stand 2012;27(10):49-56; quiz 58.

36. Jeyakumar A, Rahman SI, Armbrecht ES et al. The association between sleep-disordered breathing and enuresis in children. Laryngoscope 2012;122(8):18737. 